\title{
Equilíbrio higroscópico da palma forrageira: Relação com a umidade ótima para fermentação sólida ${ }^{1}$
}

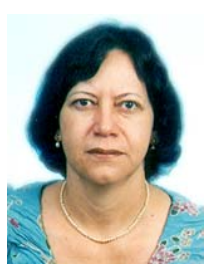

Lúcia de F. Araújo² ${ }^{2}$ Líbia de S. C. Oliveira ${ }^{3}$, Américo Perazzo Neto ${ }^{4}$ Odelsia L.S. de Alsina ${ }^{3}$ \& Flávio L.H. da Silva ${ }^{3}$

\author{
1 Trabalho extraído de parte da Tese de Doutorado do primeiro autor \\ ${ }^{2}$ EMEPA/PB. Rua Eurípedes Tavares, 210, Tambiá, CEP 58013-290, João Pessoa, PB. Fone (83) 3218-5490. \\ E-mail: lucia@yahoo.com.br (Foto) \\ ${ }^{3}$ DEQ/CCT/UFCG. Av. Aprígio Veloso, 882, Bodocongó, CEP 58109-970, Campina Grande, PB. Fone (83) $3310-1113$. \\ E-mail: flhs@deq.ufcg.edu.br \\ ${ }^{4}$ DF/CCA//UFPB. Cidade universitária, CEP 58397-000, Areia, PB. Fone (83) 3362-2300
}

Protocolo 112 - 10/8/2004 - Aprovado em 14/1/2005

\begin{abstract}
Resumo: No estudo do processo de enriquecimento protéico da palma forrageira (Opuntia ficusindica Mill) através da levedura Saccharomyces cerevisiae em meio semi-sólido, a atividade de água é uma das variáveis que mais afetam não apenas o processo fermentativo mas, também, o armazenamento desse enriquecido; desta forma, o presente trabalho foi realizado com o objetivo de se obter isotermas de dessorção da cactácea palma forrageira, nas temperaturas usuais dos processos das fermentações, 30, 35 e $40{ }^{\circ} \mathrm{C}$, de modo a correlacionar atividade de água e umidade. As isotermas obtidas foram analisadas mediante os modelos de GAB e BET sendo que, em geral, o modelo de GAB foi o que melhor se ajustou aos dados experimentais. A partir das isotermas obtidas, encontraram-se as faixas de umidades adequadas para obtenção das atividades de água recomendadas para o processo fermentativo e durante o armazenamento do enriquecido.
\end{abstract}

Palavras-chave: Opuntia ficus-indica Mill, atividade de água, modelo de GAB, modelo de BET, armazenamento

\section{Hygroscopic equilibrium of the cactus pear: Relation with the optimum moisture for the solid fermentation}

\begin{abstract}
In the study of the protein enrichment process of the cactus pear (Opuntia ficusindica Mill) through the yeast Saccharomyces cerevisiae in semi-solid state fermentation, the water activity is one of the variables that most affects the fermentation process as well as the storage. The present work had the objective of obtaining isotherms of sorption of the cactus pear, in the usual temperatures of the fermentations processes, 30,35 and $40^{\circ} \mathrm{C}$, in order to correlate water activity and moisture content. The obtained isotherms were analyzed by the GAB and BET models, the GAB model being, in general, the one that adjusted better to the experimental data. The isotherms allowed to find appropriate moisture content to obtain the water activities recommended for the fermentation process as well as during the storage of this enriched product.
\end{abstract}

Key words: Opuntia ficus-indica Mill, water activity, GAB model, BET model, storage

\section{INTRODUÇÃO}

Desde o início do século, a palma forrageira é cultivada com relativo sucesso no semi-árido nordestino e nas regiões áridas e semi-áridas dos Estados Unidos, México, África do Sul e Austrália, tendo sido introduzida no Brasil em 1880, no Estado de Pernambuco, por meio de raquetes provenientes do Texas, EUA (Domingues, 1963). Conforme Teixeira et al. (1999) a palma forrageira foi adotada, no Brasil, por apresentar características morfofisiológicas que a tornam apropriada a regiões semi-áridas, constituindo-se uma das mais importantes bases de alimentação para bovinos. Na região do Nordeste brasileiro, estima-se uma área plantada com palma forrageira em torno de 550.000 ha, destacando-se Pernambuco e Alagoas, estados que possuem, no momento, a maior área cultivada com esta cactácea.

A estacionalidade da produção de forragem na região semiárida é provocada pela distribuição irregular das chuvas associada a um manejo de pastagem deficiente, resultando em baixa disponibilidade de forragem durante o período de estiagem; 
deste modo e neste período, os criadores da região recorrem ao uso de concentrados comerciais para uma suplementação protéica que venha suprir as necessidades nutritivas do rebanho; no entanto, os freqüentes aumentos dos preços da suplementação protéica utilizada na alimentação animal vêm tornando a atividade pecuária antieconômica (Araújo et al., 2003). Este desafio tem estimulado o interesse pelo aproveitamento de alimentos não convencionais na indústria de alimentação animal do Brasil.

Do ponto de vista da nutrição animal, as Opuntias contêm alto teor de umidade (cerca de $85 \%$ ), alta digestibilidade in vitro (cerca de $75 \%$ ) e alto conteúdo de vitamina $\mathrm{A}$, apresentam $29 \mu \mathrm{g}$ de carotenóides e $13 \mathrm{mg}$ de ácido ascórbico por $100 \mathrm{~g}$ de cladódios, matéria orgânica (67\%), energia $\left(2,61 \mathrm{Mcal} \mathrm{kg}^{-1}\right)$, fibras cruas (4,3\%), P (0,08-0,18\%), Ca (4,2\%), K (2,3\%) e Mg $(1,4 \%)$, mas com baixo teor de proteína (cerca de $5 \%$ ) (González, 1989; Gregory \& Felker, 1992; Santos et al., 1992; FAO, 2001).

Embora a palma forrageira possua características adaptáveis às condições adversas da região, por outro lado apresenta limitações em relação ao teor de proteínas e vitaminas, mostrando-se inferior às outras culturas forrageiras. Com o cultivo de microrganismos como fungos, este vegetal pode aumentar seu valor nutricional, sendo acrescido de proteína microbiana, sais como fosfato, potássio e cálcio, além de vitaminas do complexo B, importantes fatores de crescimento para os animais (Villas Bôas \& Esposito, 2000; Araújo et al., 2003).

Dentre os produtos que podem substituir os suplementos protéicos, destacam-se os microrganismos (algas, bactérias, fungos e leveduras), considerados uma fonte protéica unicelular de elevado teor protéico, além de possuírem rápido crescimento e possibilidade de cultivo em diversos substratos.

Dos vegetais disponíveis na região que apresentam características favoráveis ao desenvolvimento desses microrganismos, destaca-se a palma forrageira. Araújo (2004) estudou o processo de enriquecimento protéico da palma forrageira utilizando o microrganismo Saccharomyces cerevisiae. O valor máximo de teor protéico alcançado nas condições estudadas foi superior a $26 \%$, sendo este teor compatível ou maior que os concentrados convencionais utilizados como suplemento protéico para a ração animal. O concentrado protéico da palma obteve alto índice de digestibilidade in vitro $(95,8 \%)$ e não apresentou grande alteração no valor da energia bruta, se comparada com a palma in natura.

As cactáceas são materiais higroscópicos, isto é, materiais capazes de absorver, reter ou eliminar água, que procuram sempre estabelecer um equilíbrio de umidade com o ar em seu redor. A água causa sempre aumento da pressão de vapor sobre a superfície das mesmas. Quando esta pressão e a pressão de vapor de água da atmosfera são iguais, ocorre equilíbrio de umidade.

Santin (1996) afirma que o crescimento dos microrganismos depende da atividade de água, em razão da influência da pressão osmótica sobre as trocas através das membranas. $\mathrm{O}$ intervalo da atividade de água no qual são observados os desenvolvimentos microbianos, varia de 0,60 a 0,99 ; em geral, o valor ótimo para o crescimento se situa entre 0,90 e 0,99 ; abaixo disso, o crescimento é moderado, retardado ou inibido; assim, todo microrganismo é caracterizado por um valor de atividade de água (aw) mínimo, abaixo do qual não mais se pode desenvolver. Segundo Catão (1998) dentre os atributos que permitem o crescimento de microrganismos agindo na destruição de produtos agrícolas, inclui-se a habilidade para crescer em níveis de atividade de água reduzida, dentro de uma faixa de 0,65 a 0,95 ou acima. De acordo com Pelizer et al. (2003) a atividade de água influencia o crescimento microbiano e processos biológicos e enzimáticos. Cada microrganismo possui um limite mínimo de atividade de água para realizar suas atividades metabólicas. Portanto, a atividade de água ótima para fungos é em torno de 0,70 ; para leveduras $0,80 \mathrm{e}$, para bactérias, 0,90 .

Com relação ao armazenamento para a conservação do produto enriquecido, não se utilizando aditivos nem refrigeração, a faixa ótima de atividade de água residual deve estar compreendida entre 0,25 e 0,35 eliminando, desta maneira, qualquer crescimento de microrganismos (Santin, 1996).

Devido a atividade de água ser uma variável de vital importância no estudo de fermentação de enriquecimento protéico em estado semi-sólido, visto esta variável poder ser limitante no processo, objetivou-se, neste trabalho, levantar isotermas de dessorção da cactácea palma forrageira nas temperaturas de 30,35 e $40^{\circ} \mathrm{C}$, ajustando-se os dados através da aplicação de modelos matemáticos para correlacionar atividade de água e umidade, quantificando, desta forma, a atividade ótima para o estudo do processo de crescimento de microrganismo (cultivo de microrganismos na cactácea) para obtenção de enriquecimento protéico e a faixa ideal de umidade para armazenamento da cactácea enriquecida, para ser utilizada como suplemento protéico na alimentação dos animais, em períodos de estiagem.

\section{MATERIAL E MÉTODOS}

\section{Matéria-prima}

A matéria-prima utilizada foi a palma forrageira (Opuntia ficus-indica Mill) cultivada no campo experimental instalado na microrregião do Cariri Paraibano, no município de Soledade, nas bases físicas da Fazenda Donana, cujo solo de classe $\mathrm{NCg}$ (Bruno não-cálcico) apresentando clima do tipo Bsh semi-árido quente, temperatura máxima de 36 e mínima de $16^{\circ} \mathrm{C}$, com média nunca inferior a $24^{\circ} \mathrm{C}$, caracteriza-se pela grande irregularidade do regime pluviométrico. A vegetação dominante é a caatinga hiperxerófila, que em toda a área tem parte arbustiva ou arbórea, com grande quantidade de cactáceas e bromeliáceas.

\section{Teor de umidade e atividade de água}

Análise do teor de umidade: Para determinação do teor de umidade da palma forrageira, foi utilizada a metodologia da AOAC (1990). Para pesagem, as amostras foram resfriadas em dessecador. As umidades de equilíbrio (em base seca) foram calculadas através da Eq.1.

$$
\mathrm{Xbs}=\frac{\mathrm{m}_{\mathrm{i}}-\mathrm{m}_{\mathrm{s}}}{\mathrm{m}_{\mathrm{s}}}
$$


em que:

Xbs - umidade na base seca, $\mathrm{g} \mathrm{g}^{-1}$

$\mathrm{m}_{\mathrm{i}}$ - massa inicial da amostra, $\mathrm{g}$

$\mathrm{m}_{\mathrm{s}}$ - massa seca da amostra, $\mathrm{g}$

Análise de atividade de água: O levantamento dos dados das isotermas de dessorção da palma forrageira foi realizado no equipamento Termoconstanter Novasina TH200, instrumento projetado para a medida de atividade de água (Figura 1). Neste equipamento, a temperatura da câmara de medição onde foram colocadas as amostras, é regulada por meio de um controlador localizado na frente do mesmo, que serve para fixar o valor da temperatura desejada com variação menor que $0,2^{\circ} \mathrm{C}$, em toda a sua área de trabalho, que é de 0 a $50^{\circ} \mathrm{C}$. A referida câmara, combinada com o regulador de temperatura, forma um mini gabinete climático. Ela é equipada com um sensor de umidade e de temperatura - enBSK Novasina. Este sensor mede a atividade e temperatura de quantidades de amostras pequenas do material, como pós, granulados, pastas e líquidos. Este equipamento possui o transmissor RTD-200, que converte os sinais da célula de medição. Os valores medidos de umidade relativa (atividade de água) e de temperatura, podem ser lidos diretamente no mostrador do painel dianteiro.

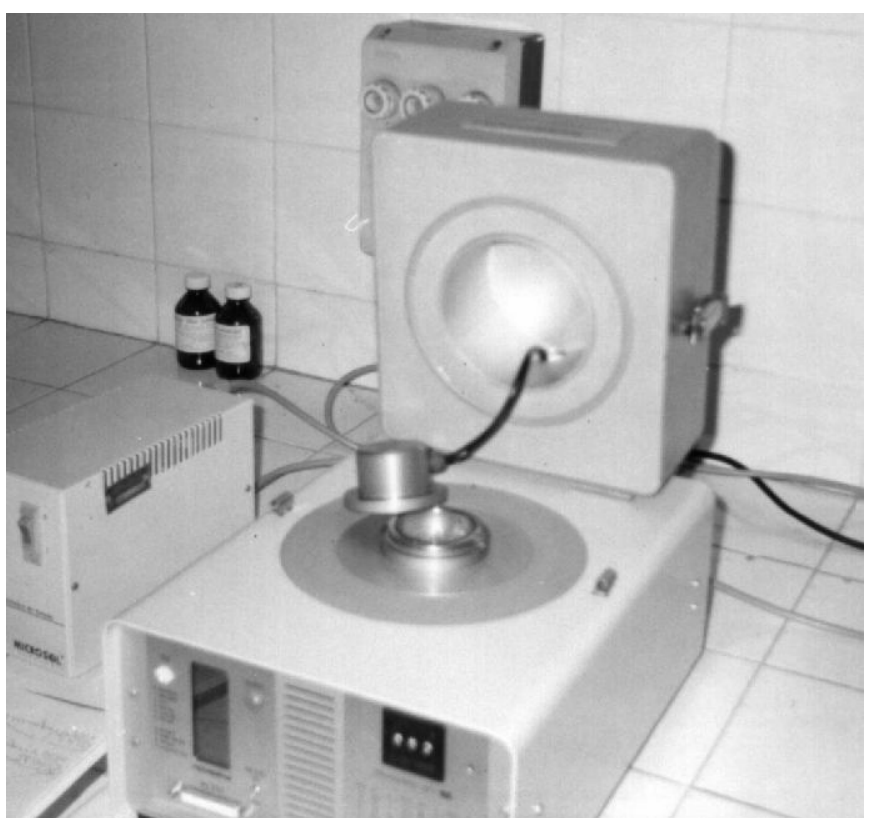

Figura 1. Equipamento de análise de atividade da água

Inicialmente, as amostras de 6,0 $\mathrm{g}$ aproximadamente (pequenos pedaços de palma forrageira) foram colocadas dentro de células que acompanham o aparelho e, após serem pesadas, foram levadas à estufa, regulada a $70^{\circ} \mathrm{C}$ pelo período de $3 \mathrm{~h}$, onde sofreram um processo suave de secagem. Após este período na estufa, as amostras foram retiradas e colocadas em um dessecador, a fim de uniformizar a distribuição de água na amostra. Posteriormente, as células, contendo as amostras, foram levadas ao equipamento Thermoconstanter Novasina TH200 para determinação da atividade de água das amostras, através do sensor enBSK Novasina.

As amostras ficaram no equipamento, até que a leitura (número do mostrador) fosse estabilizada para, então, serem retiradas e pesadas em uma balança analítica com $0,1 \mathrm{mg}$ de precisão. Depois de pesadas elas retornaram para a estufa e aí permaneceram 20 min em média para, em seguida, se fazer a próxima leitura. As sucessões dessas leituras indicaram os pontos da curva da isoterma de dessorção da palma forrageira, para a temperatura determinada; uma outra amostra permaneceu na mesma estufa, durante $24 \mathrm{~h}$, para determinação da massa seca.

\section{Modelos matemáticos para ajuste das isotermas}

Para se ajustar os dados experimentais das isotermas, é necessário utilizar-se modelos matemáticos e fazer a correspondência entre teor de umidade do produto analisado (Xbs) e atividade de água (aw), fornecendo informações importantes sobre o fenômeno de sorção, tais como a água absorvida na monocamada molecular ou o calor de sorção para as camadas subseqüentes.

Existem vários modelos matemáticos, dentre eles os mais difundidos são: modelo de BET e o modelo de GAB.

Modelo de BET: A equação de BET (Brunauer-Emmer-Teller) é o modelo mais conhecido e usado com sucesso para atividade de água até valores em torno de 0,6 (Park \& Nogueira, 1992). O modelo tem sido utilizado para grande variedade de alimentos situados nos intervalos correspondentes a $0,05<$ aw $<0,6$, sendo expresso pela Eq.2.

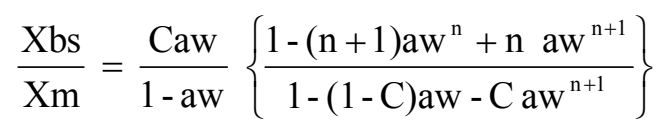

em que:

aw - atividade de água

C - constante de BET

Xbs - conteúdo de umidade de equilíbrio expressa em base seca, $\mathrm{g} \mathrm{g}^{-1}$

$\mathrm{Xm}$ - conteúdo de umidade na monocamada molecular, $\mathrm{g} \mathrm{g}^{-1}$

n - número de camadas moleculares

Modelo de GAB: A equação de GAB (Guggenheim-Andersonde Boer) de três parâmetros é um reforço das teorias de BET e Langmuir. Tem sido sugerida por muitos pesquisadores e está sendo utilizada em diversos laboratórios de alimento nos EUA e na comunidade européia, como padrão de descrição e comparação de isotermas (Lomauro et al., 1985; Park et al., 2001). O modelo de GAB é expresso pela Eq.3.

$$
\frac{\mathrm{Xe}}{\mathrm{Xm}}=\frac{\mathrm{aw} \cdot \mathrm{C}_{\mathrm{GAB}} \cdot \mathrm{K}_{\mathrm{GAB}}}{\left(1-\mathrm{K}_{\mathrm{GAB}} \cdot \mathrm{aw}\right)\left(1-\mathrm{K}_{\mathrm{GAB}} \cdot \mathrm{aw}+\mathrm{C}_{\mathrm{GAB}} \cdot \mathrm{K}_{\mathrm{GAB}} \cdot \mathrm{aw}\right)}
$$

em que:

aw - atividade de água

Xbs - conteúdo de umidade de equilíbrio expresso na matéria seca, $\mathrm{g} \mathrm{g}^{-1}$

$\mathrm{Xm}$ - conteúdo de umidade na monocamada, $\mathrm{g} \mathrm{g}^{-1}$ 
$\mathrm{C}_{\mathrm{GAB}}$ e $\mathrm{K}_{\mathrm{GAB}}$ são as constantes de adsorção, relacionadas com as interações energéticas entre as moléculas da monocamada e as subseqüentes, em um sítio de sorção. Observa-se, no modelo que, quando $\mathrm{K}_{\mathrm{GAB}}$ é igual à unidade, esta equação se reduz à equação de BET, com dois parâmetros.

\section{RESULTADOS E DISCUSSÃO}

A Figuras 2 (A, B e C), apresenta as isotermas de dessorção da palma forrageira, nas temperaturas de 30,35 e $40{ }^{\circ} \mathrm{C}$, respectivamente, ajustadas pelo modelo de BET. Observa-se, através da Tabela 1 , que os coefícientes de correlação $\left(\mathrm{R}^{2}\right)$

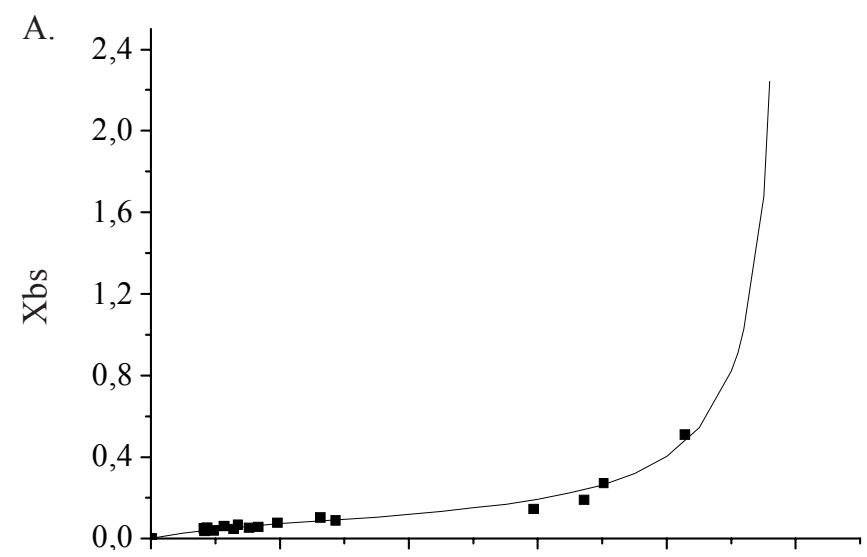

B.

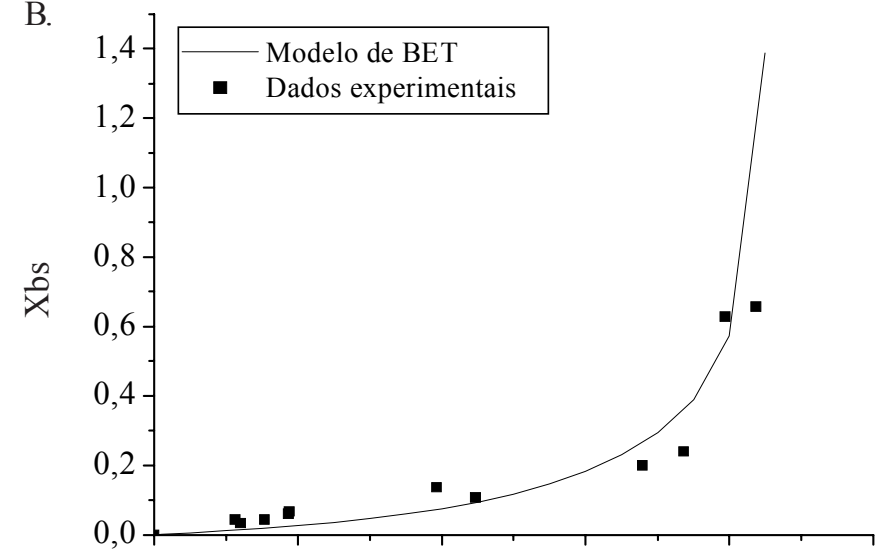

C.

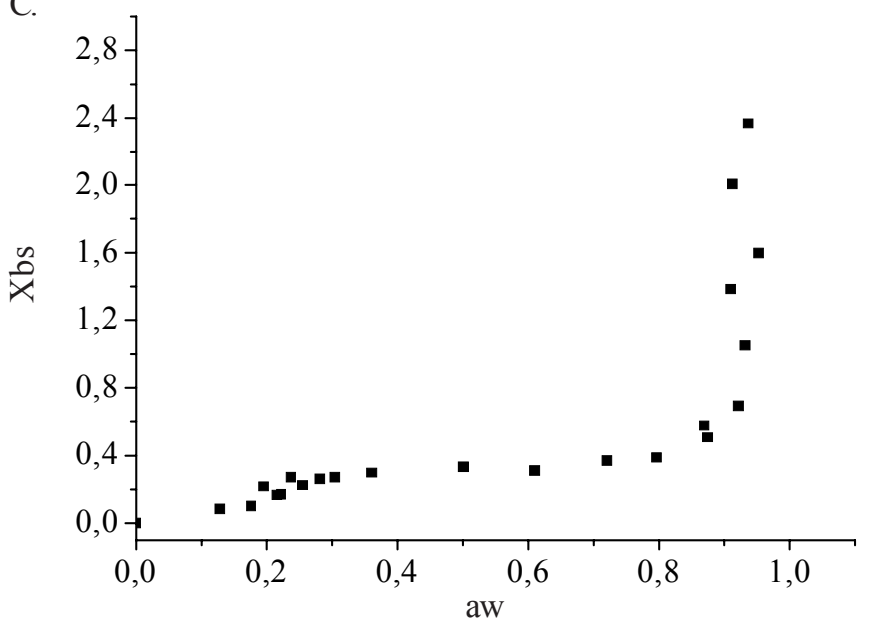

Figura 2. Isotermas de dessorção da palma forrageira, nas temperaturas de 30 (A), 35 (B) e $40{ }^{\circ} \mathrm{C}(\mathrm{C})$, ajustadas pelo modelo de BET
Tabela 1. Parâmetros do modelo de BET

\begin{tabular}{ccccc}
\hline Temperatura $\left({ }^{\circ} \mathrm{C}\right)$ & $\mathrm{X}_{\mathrm{m}}$ & $\mathrm{C}$ & $\mathrm{n}$ & $\mathrm{R}^{2}$ \\
\hline 30 & 0,083 & 9,1 & 156 & 0,99 \\
35 & 0,143 & 0,69 & 37 & 0,96 \\
\hline
\end{tabular}

foram de 0,99 e 0,96 para as temperaturas de 30 e $35^{\circ} \mathrm{C}$, respectivamente.

Os resultados encontrados na Tabela 1 mostram os parâmetros do modelo de BET para o ajuste dos dados experimentais das isotermas da palma forrageira, para as temperaturas de 30 e $35^{\circ} \mathrm{C}$. Não houve bom ajuste na temperatura de $40^{\circ} \mathrm{C}$, sendo o coeficiente de correlação $\left(\mathrm{R}^{2}\right)$ menor que 0,87 . Desta forma, fez-se opção, nesta temperatura, por apresentar apenas a curva dos dados experimentais. Observa-se, através da mesma, que o parâmetro $\mathrm{X}_{\mathrm{m}}$ aumenta com o aumento da temperatura; já com o parâmetro $\mathrm{C}$ ocorre o contrário, ou seja, diminui com o aumento da temperatura e, com relação ao parâmetro n, verifica-se uma diminuição de 30 a $35^{\circ} \mathrm{C}$. Lahsasni et al. (2003) encontraram perfis dos valores dos parâmetros $\mathrm{X}_{\mathrm{m}} \mathrm{e} \mathrm{C}$ diferentes deste trabalho, ou seja, estudando as isotermas de dessorção nas temperaturas de 30,40 e $50{ }^{\circ} \mathrm{C}$ do cladódio da palma forrageira, utilizando o modelo de BET linearizado, verificaram que o parâmetro $\mathrm{X}_{\mathrm{m}}$ decresce e o parâmetro $\mathrm{C}$ aumenta com o aumento da temperatura. Foi utilizado o modelo de BET linearizado para determinação dos parâmetros $\mathrm{X}_{\mathrm{m}} \mathrm{e} \mathrm{C}$ nas temperaturas de estudo neste trabalho, encontrando-se ajustes não satisfatórios $\left(\mathrm{R}^{2} \mathrm{em}\right.$ torno de 0,7$)$.

Apesar das restrições do uso do modelo de BET para atividade de água (aw) acima de 0,60, verifica-se que, neste caso, o modelo ajusta os dados experimentais nas temperaturas de 30 e $35^{\circ} \mathrm{C}$.

A Figura 3 apresenta as isotermas de dessorção da palma forrageira nas temperaturas de 30,35 e $40^{\circ} \mathrm{C}$, respectivamente, ajustadas pelo modelo de GAB. Observa-se bom ajuste para toda faixa de temperatura estudada, cujos valores de coeficiente de correlação $\left(\mathrm{R}^{2}\right)$ estão apresentados na Tabela 2 , acima de 0,95; na Tabela 2 apresenta-se, ainda os parâmetros do modelo de $\mathrm{GAB}$, em função da temperatura. A fração de umidade na monocamada $\left(\mathrm{X}_{\mathrm{m}}\right)$ indica o mesmo comportamento verificado no modelo de BET, ou seja, cresce com o aumento da temperatura; enfim, os valores de $\mathrm{C}$ decrescem com o aumento da temperatura e o valor de $\mathrm{K}$ ficou praticamente constante.

As formas das isotermas obtidas nas temperaturas estudadas seguem sempre o tipo III de classificação de BET, em forma de J. Essas formas são típicas de produtos com altas concentrações de açúcares e solutos e que apresentam pouca adsorção por capilaridade (Park \& Nogueira, 1992).

Santin (1996) apresenta valores de atividade de água mínimos para o crescimento de alguns microrganismos e, afirma que abaixo destes valores, o crescimento da célula microbiana cessa. Para a levedura S. cerevisiae (microrganismo utilizado

Tabela 2. Parâmetros do modelo de GAB

\begin{tabular}{crrrc}
\hline Temperatura $\left({ }^{\circ} \mathrm{C}\right)$ & $\mathrm{X}_{\mathrm{m}}$ & $\mathrm{C}_{\mathrm{GAB}}$ & $\mathrm{K}_{\mathrm{GAB}}$ & $\mathrm{R}^{2}$ \\
\hline 30 & 0,063 & 23,85 & 1,06 & 0,99 \\
35 & 0,073 & 6,40 & 1,07 & 0,97 \\
40 & 0,154 & 2,04 & 0,97 & 0,95 \\
\hline
\end{tabular}


A.

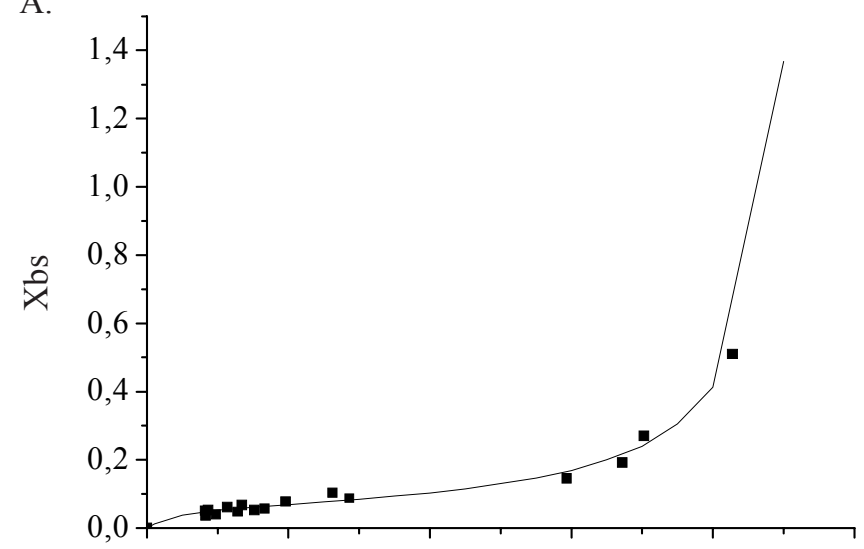

B.

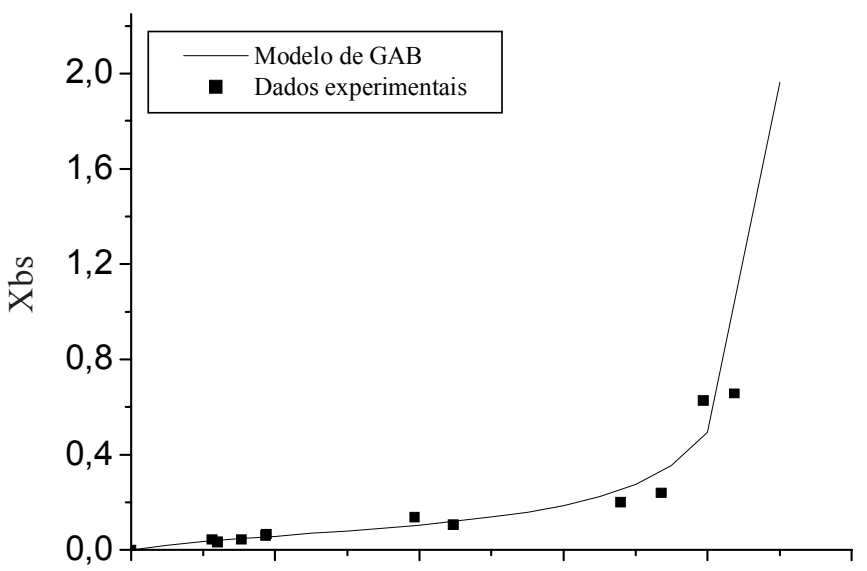

C.

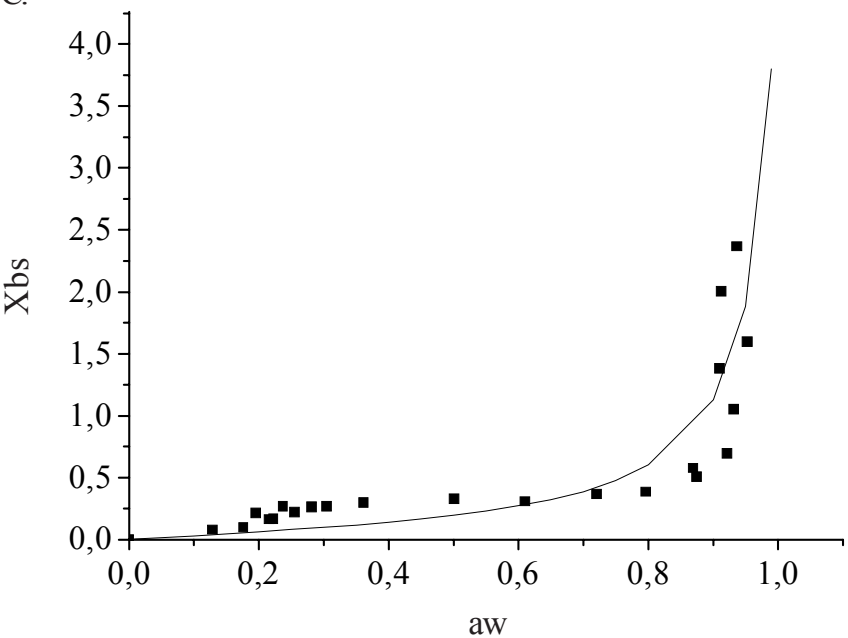

Figura 3. Isotermas de dessorção da palma forrageira, na temperatura de 30 (A), 35 (B) e $40{ }^{\circ} \mathrm{C}(\mathrm{C})$, ajustadas pelo modelo de GAB

para o processo de enriquecimento protéico da cactácea) a atividade de água mínima de crescimento está em torno de 0,89 . Operando-se, inicialmente, o processo de fermentação com o substrato abaixo de 0,89 , o crescimento da levedura (inóculo utilizado no trabalho de estudo do processo de enriquecimento protéico) é inibido, podendo não se desenvolver. A faixa ótima para o crescimento da levedura está entre 0,90 e 0,99 da aw do substrato (Gould, 1989).

A Tabela 3 apresenta os valores aproximados de Xbs para a palma forrageira, para o metabolismo e crescimento da
Tabela 3. Valores de Xbs obtidos através dos modelos de BET e GAB, correlacionando aw acima de 0,9 (processo fermentativo) e abaixo de 0,35 (armazenamento) para a cactácea palma forrageira

\begin{tabular}{ccclcc}
\hline & \multicolumn{2}{c}{ aw acima de 0,9} & & \multicolumn{2}{c}{ aw abaixo de 0,35} \\
\cline { 2 - 3 } \cline { 6 - 6 } Temperatura $\left({ }^{0} \mathrm{C}\right)$ & BET & GAB & & BET & GAB \\
\hline 30 & $>1,00$ & $>1,20$ & & $<0,18$ & $<0,18$ \\
35 & $>1,40$ & $>1,50$ & & $<0,10$ & $<0,18$ \\
40 & $>2,00$ & $>1,50$ & & $<0,10$ & $<0,18$ \\
\hline
\end{tabular}

levedura (operação do processo de enriquecimento protéico), tendo como referência a atividade de água acima de 0,90 (Gould, 1989) e nas condições ótimas para a conservação do produto enriquecido (armazenamento), não se utilizando aditivos nem refrigeração.

A faixa ideal de atividade de água (aw) residual deve estar compreendida entre 0,25 a 0,35 eliminando, desta forma, qualquer crescimento de microrganismos (Santin, 1996).

Para que os enriquecidos (fermentados) tenham atividades de água abaixo de 0,35 , objetivando-se o seu armazenamento, é conveniente a utilização da operação unitária de secagem. Conforme a literatura (Dural \& Hines, 1993) não se deve retirar água em quantidade inferior a monocamada, uma vez que este é o limite de conservação de nutrientes do alimento e há um dispêndio maior de energia para a sua eliminação.

Objetivando a fermentação para enriquecer a cactácea, devese iniciar o processo com umidade da palma forrageira acima de $90 \%$, o que corresponde a atividade de água acima de 0,9 e para a conservação e manutenção da qualidade da cactácea enriquecida seca, é necessário ter no máximo de Xbs, aproximadamente, de 0,18 , que corresponde a umidade residual do enriquecido de $15 \%$ e aw abaixo de 0,35 para as três temperaturas estudadas.

\section{CONCLUSÕES}

1. As formas das isotermas seguem o tipo III da classificação de BET.

2. Em geral, o modelo de GAB ajustou melhor os dados experimentais das isotermas nas temperaturas em estudo.

3. No processo de fermentação para enriquecer a cactácea, a umidade da palma forrageira deve estar acima de $90 \%$, o que corresponde à atividade de água acima de 0,9 .

4. Na fermentação para enriquecer a cactácea, deve-se iniciar o processo com umidade da palma forrageira acima de $90 \%$, atividade de água acima de 0,9 . Para a conservação e manutenção da qualidade da cactácea enriquecida seca, é necessário ter no máximo de Xbs, aproximadamente, de 0,18 , umidade residual do enriquecido de $15 \%$ e aw abaixo de 0,35 para as três temperaturas estudadas.

\section{LITERATURA CITADA}

AOAC - Association of Official Analytical Chemists. Official methods of analysis, v.1, Arlington: AOAC, 1990. vp. 
Araújo, L.F. Enriquecimento protéico do mandacaru sem espinho (Cereus jamacaru L.) e palma forrageira (Opuntia ficus-indica Mill) por fermentação semi-sólida. Campina Grande: UFCG, 2004, 175p. Tese Doutorado

Araújo, L.F.; Medeiros, A.N.; Perazzo Neto, A.; Conrado, L.S.; Silva, F.L.H. Estudo do enriquecimento protéico do mandacaru sem espinhos (Cereus jamacaru P. DC), utilizando levedura por fermentação semi-sólida. In: Simpósio Nacional de Fermentação, 6, 2003, Florianópolis, Anais... Florianópolis: SNF, 2003. CD Rom.

Catão, M.N.S. Identificação de fungos filamentosos e contaminantes na farinha de mandioca (Manihot esculenta Crantz) comercializada em João Pessoa. In: Congresso Brasileiro de Ciência e Tecnologia de Alimentos, 16, 1998, Rio de Janeiro, Anais... Rio de Janeiro: SBCTA, 1998. v.1, p.919-922.

Domingues, O. Origem e introdução da palma forrageira no Nordeste. Recife: Instituto Joaquim Nabuco de Pesquisas Sociais, 1963, 73p.

Dural, N.H.; Hines, A.L. A new theoretical isotherms equation for water vapor-food systems: multilayer adsorption on heterogeneous surfaces. Journal of Food Engineering, New York, v.20, n.1, p.75-96, 1993.

FAO. Food and Agriculture Organization of the United Nations. Agroecologia, cultivo e usos da palma forrageira. João Pessoa: SEBRAE/PB, 2001, 216p.

González, C.L. Potential of fertilization to improve nutritive value of pricklypear cactus (Opuntia lindheimeri Engelm.). Journal of Arid Environments, Buenos Aires, v.16, n.1, p.87-94, 1989.

Gould, G.W. Drying, raised osmotic pressure and low water activity. In: Gould, G.V. (ed). Mechanisms of action of food preservation procedures. Applied Science. London: Elsevier $1989,117 \mathrm{p}$.

Gregory, R.A.; Felker, P. Crude protein and phosphorus contents of eight constrasting Opuntia forage clones. Journal of Arid Environment, London, v.22, n.4, p.323-331, 1992.
Lahsasni, S.; Kouhila , M.; Mahrouz, M.; Fliyou, M. Moisture adsorption-desorption isotherms of prickly pear cladode (Opuntia ficus indica) at diferent temperatures. Energy Conversion and Management, New York, v.44, n.1, p.923936. 2003.

Lomauro, C.J.; Bakshi, A.S.; Labuza, T.P. Evaluation of food moisture sorption isotherm equations. LebensmittelWirssenschaft and Techonologies, London, v.18, n.2, p.111117, 1985.

Park, K.J.; Bin, A.; Brod, F.P.R. Obtenção das isotermas de sorção e modelagem matemática para a pêra bartlett (Pyrus sp.) com e sem desidratação osmótica. Ciência e Tecnologia de Alimentos, Campinas, v.21, n.1, p.73-77, 2001.

Park, K.J.; Nogueira, R.I. Modelos para ajuste de isoterma de sorção de alimentos, Engenharia Rural, Piracicaba, v.3, n.1, p.80-86, 1992.

Pelizer, L.H.; Danesi, E.D.G.; Rangel, C.O.; Sassano, C.E.N.; Sato, S.; Moraes, I.O. Influence of inoculum age and concentration in Spirulina platensis cultivation. Journal of Food Engineering, New York, v.56, n.3, p.371-375, 2003.

Santin, A.P. Estudo da secagem da inativação de leveduras (Saccharomyces cerevisiae). Florianópolis: UFSC, 1996. 150p. Dissertação Mestrado

Santos, M.V.E.; Lira, M. de A.; Farias; I. Efeito do período de armazenamento pós-colheita sobre o teor de matéria seca e composição química das palmas forrageiras. Pesquisa Agropecuária Brasileira, Brasília, v.27, p.777-783, 1992.

Teixeira, J.C.; Evangelista, A.R.; Perz, J.R.O.;Trindade, I.A.C.M.; Moron, I.R. Cinética da digestão ruminal da palma forrageira. Ciência e Agrotecnologia, Lavras, v.23, n.1, p.179-186, 1999.

Villas Bôas, S.G.; Esposito, E. Bioconversão do bagaço de maçã: enriquecimento nutricional utilizando fungos para produção de um alimento alternativo de alto valor agregado. Revista de Biotecnologia, Brasília, v.1, n.14, p.38-42, 2000. 